Article

\title{
Grain Boundary Evolution of Cold-Rolled FePd Alloy during Recrystallization at Disordering Temperature
}

\author{
Hung-Pin Lin ${ }^{1}$, Delphic Chen ${ }^{2,3}$ and Jui-Chao Kuo ${ }^{1, *}$ \\ 1 Department of Materials Science and Engineering, National Cheng-Kung University, \\ Tainan 70101, Taiwan; E-Mail: n5896115@mail.ncku.edu.tw \\ 2 Department of Materials and Optoelectronic Science, National Sun Yat-Sen University, \\ Kaohsiung 80424, Taiwan; E-Mail: delphi.home@msa.hinet.net \\ 3 Research Center for Physical Properties and Microstructure of Metals, \\ National Sun Yat-Sen University, Kaohsiung 80424, Taiwan \\ * Author to whom correspondence should be addressed; E-Mail: jckuo@mail.ncku.edu.tw; \\ Tel./Fax: +886-6-275-4194.
}

Academic Editor: Jung Ho Je

Received: 20 April 2015 / Accepted: 26 May 2015 / Published: 4 June 2015

\begin{abstract}
In this study, the grain boundary character and texture of $50 \%$ and $90 \%$ cold-rolled FePd alloy was investigated during recrystallization at $700{ }^{\circ} \mathrm{C}$. Electron backscatter diffraction (EBSD) measurements were performed on the rolling direction to normal direction section. Kernel average misorientation (KAM) calculated from EBSD measurements was employed to determine the recrystallization fraction. The Avrami exponent $\mathrm{n}$ of recrystallization is 1.9 and 4.9 for $50 \%$ and $90 \%$ cold rolling, respectively. The new formation of texture reveals random texture during the recrystallization process. As annealing time increased, the number of high angle boundary (HAGB) and coincidence site lattice (CSL) increased with consumption of low angle boundary (LAGB). In addition, possible transformations between different grain boundaries are observed here.
\end{abstract}

Keywords: kernel average misorientation (KAM); electron backscatter diffraction (EBSD); recrystallization; FePd; low angle boundary (LAGB) 


\section{Introduction}

FePd, FePt, and CoPt alloys with L10-ordered structures present potential applications in advanced gas-turbine and combustion engines, permanent magnet micro-devices, and data storage media [1-4]. One important feature that these alloys should present is operability at temperatures higher than $400{ }^{\circ} \mathrm{C}$ [5]. The Curie temperature $T_{\mathrm{C}}$ of FePd alloys is higher than $490{ }^{\circ} \mathrm{C}$ [6], and high saturation induction $B \mathrm{~s}$ approximates $1.38 \mathrm{~T}$ [3]. Compared with those of FeCo alloys, the $T_{\mathrm{C}}$ and $B \mathrm{~s}$ of FePd alloys are lower. However, FePd alloys present better ductile and corrosion resistance properties [6].

After a brief discussion on magnetic properties, we focus on recrystallization texture behavior. Disordered FePd alloys, such as brass, silver, and austenitic stainless steels, have low stacking fault energy (SFE) [3]. Several frequent texture components are indicated by name, such as the "Brass" or "B" $(\{011\}<211>)$, "Copper" or "C" $(\{211\}<111>)$, "S" $(\{123\}<634>)$, "Goss" $(\{011\}<100>)$, and "Cube" components $(\{001\}<100>)$. Smallman and Green [7] reported $\{112\}<110>$ and $\{111\}<110>$ components in the surface texture during hot rolling for austenitic stainless steels. Recrystallized non-ferrous face-centered cubic metals and alloys with low stacking fault energy present the major texture of $\{113\}<211>$ [7-12]. In 95\% cold-rolled AISI 304L austenitic stainless steel, the prominent components are Goss, Copper, and Brass in the temperature range between 600 and $1000{ }^{\circ} \mathrm{C}$ [12]. At $530{ }^{\circ} \mathrm{C}$, the recrystallization texture of $\mathrm{FePd}$ alloy reveals the evident components, $\{010\}<1101>$ and $\{054\}<22-45>$, after $50 \%$ and $90 \%$ cold-rolling, respectively [13].

Brass-type recrystallization textures are related to the deformation textures of $<111>$ rotations by approximately $30^{\circ}$ or $35^{\circ}[14]$. The $\{113\}<211>$ orientation can be derived from the Brass component by $40^{\circ}<111>$ rotation $[9,15]$. The Copper component has recently been reported to decrease in favor of the Cube component at the beginning of recrystallization [16,17]. The Brass component is subsequently consumed by the growth of Cube component, but at a considerably lower rate because of its unfavorable orientation relationship [18]. The Copper component is more rapidly consumed than the $\mathrm{S}$ component in favor of Cube component formation, which indicates the preferential nucleation of the Cube component in the transition band that possibly developed within the Copper component [19].

In addition to discussions on recrystallization texture, grain boundary migration plays an important role in primary static recrystallization. It is well known that the recrystallization takes place not only through the motion of high-angle grain boundaries [18] but also by that of low-angle grain boundaries [20-24]. However, the influence of low angle grain boundaries is usually not taken into account in experiments on the recrystallization process.

In the present study, the electron backscatter diffraction (EBSD) technique was employed to investigate the relationship between recrystallization behavior and grain boundaries in cold-rolled FePd alloy. After 50\% and $90 \%$ cold rolling, FePd alloy was annealed at the disordering temperature of $700{ }^{\circ} \mathrm{C}$ for different times. Then, EBSD measurements were performed on the transverse section (TD) of the specimens.

\section{Experimental Setup}

The detailed cold rolling procedure for FePd alloy has been described in an earlier study [25]. After $50 \%$ cold rolling, specimens were annealed at $700{ }^{\circ} \mathrm{C}$ for 1,2 , and $2880 \mathrm{~min}(48 \mathrm{~h})$; the specimens 
were annealed for 10,20 , and $60 \mathrm{~s}$ for $90 \%$ cold rolling and directly quenched in ice water. Prior to EBSD measurements, the transverse sections (TD) of the specimens were mechanically polished and then electro-polished in the electrolyte by a 4:1 mixture of acetic and perchloric acids at a charge current of $0.5 \mathrm{~mA}$ and constant voltage of $25 \mathrm{~V}$ for $30 \mathrm{~s}$.

Finally, EBSD measurements were performed on the rolling direction (RD) to the normal direction (ND) section of the specimens. Here, a field-emission electron microscope (7001F, JEOL, Tokyo, Japan) was used together with an EBSD system (EDAX/TSL Technology) with $20 \mathrm{kV}$ at a $15 \mathrm{~mm}$ working distance and a sample tilt of $70^{\circ}$. Step sizes of 0.35 and $0.15 \mu \mathrm{m}$ were selected for $50 \%$ and $90 \%$ cold rolling, respectively. In addition, OIM ${ }^{\mathrm{TM}}$ software was employed for texture and microstructure analysis after annealing.

\section{Results and Discussion}

\subsection{Determination of Recrystallization Behavior}

During recrystallization, the newly formed grains reveal a random texture. Kernel average misorientation (KAM) was used to represent local dislocation density distribution and the recrystallization fraction $[13,26]$. In principle, deformed grains have KAM $>1^{\circ}$ because of their high dislocation density, whereas recrystallized grains have $\mathrm{KAM}<1^{\circ}$. KAM maps are shown in Figures 1 and 2 for $50 \%$ and $90 \%$ cold rolling after annealing at $700{ }^{\circ} \mathrm{C}$, respectively. In this study, first, considering the case of 50\% cold rolling, the KAM distributions are shown in Figure 1b,d,f after 1 and 2 min and $48 \mathrm{~h}$ annealing. Figure 1b,d show that the KAM distributions exhibit two peaks. The intersection point of two fitting curves for 1 and $2 \mathrm{~min}$ is at $0.23^{\circ}$ and $0.41^{\circ}$. After $48 \mathrm{~h}$ annealing, only one peak is found in Figure 1f. Then, for $90 \%$ cold rolling, the KAM distributions are shown in Figure $2 \mathrm{~b}$,d,f for samples annealed at $700{ }^{\circ} \mathrm{C}$ for 10,20 , and $60 \mathrm{~s}$. The intersection point of two fitting curves is at $0.32^{\circ}$ and $0.39^{\circ}$ after 10 and $20 \mathrm{~s}$ annealing, respectively. Therefore, the recrystallization fraction can be determined by calculating the area fraction of the fitting curves obtained from the KAM distributions shown in Figure 1b,d,f and Figure 2b,d,f. Thus, recrystallization fraction as a function of time can be estimated based on the Johnson-Mehl-Avrami-Kolmogorov (JMAK) Equation [27-31]. The JMAK Equation is given as follows:

$$
X=1-\exp \left(-k t^{n}\right)
$$

where $X$ is the recrystallized fraction, $t$ is time, $k$ is the kinetic parameter, and $n$ is the JMAK (or Avrami) exponent.

According to the JMAK Equation in Figure 3 and Table 1, the Avrami exponent $n$ is 1.9 and 4.9 for $50 \%$ and $90 \%$ cold rolling, respectively. Here, the $n$ value of 1.9 approaches 2 [32], indicating one-dimensional growth, whereas 4.9, which approximates 5 and is larger than 4 [32], means three-dimensional growth at a constant nucleation rate. As reported, a value of $n>3$ correlates with ideal recrystallization for homogeneous, constant-rate nucleation [33]. In addition, the twin fractions of $50 \%$ cold rolling are $17.4 \%$ and $40.6 \%$ after 1 and $2 \mathrm{~min}$, whereas those of $90 \%$ cold rolling are $8.2 \%$ and $21.8 \%$ after 10 and $20 \mathrm{~s}$, respectively. We observed that the twin fraction of $50 \%$ cold rolling is almost double that of $90 \%$ cold rolling. The formation of twins reduces the driving force 
for recrystallization, thus retarding the process $[33,34]$. This delay can be explained by the observed $n$ value of $50 \%$ cold rolling, which is smaller than that of $90 \%$ cold rolling.

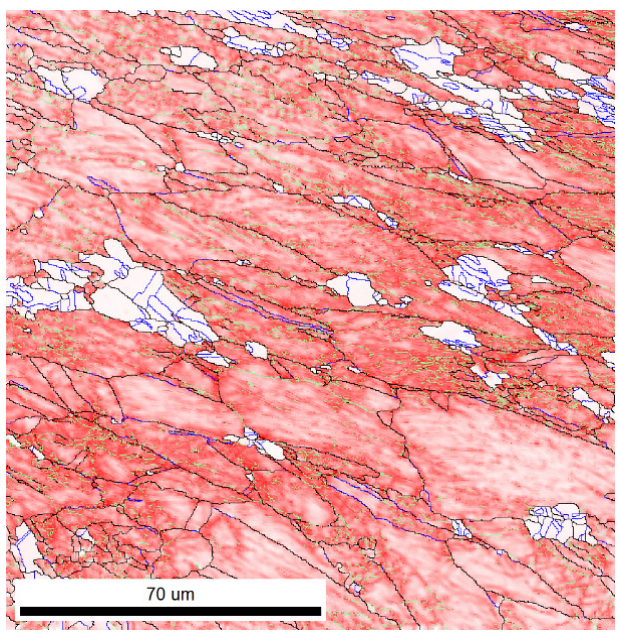

(a)

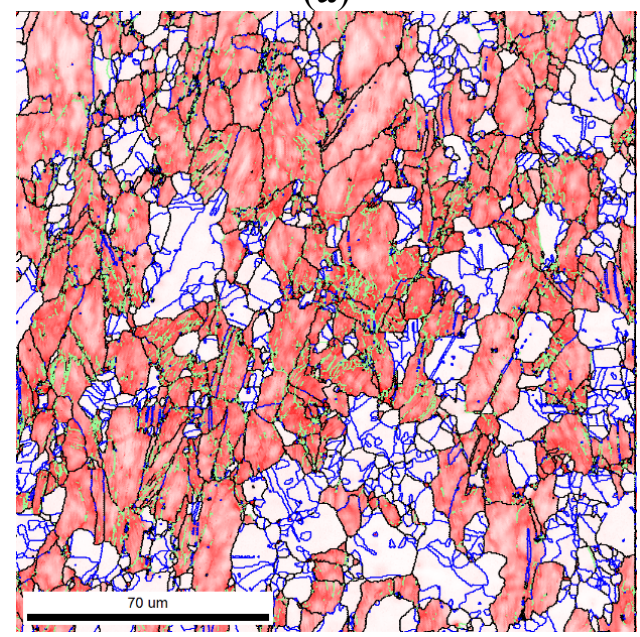

(c)

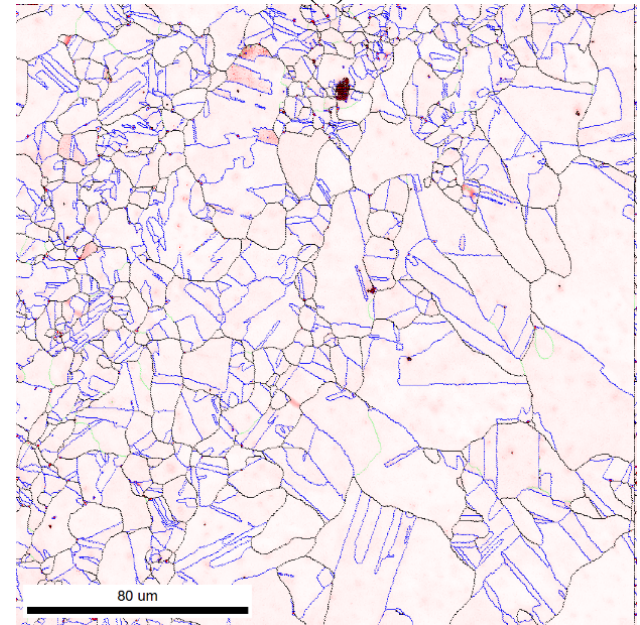

(e)

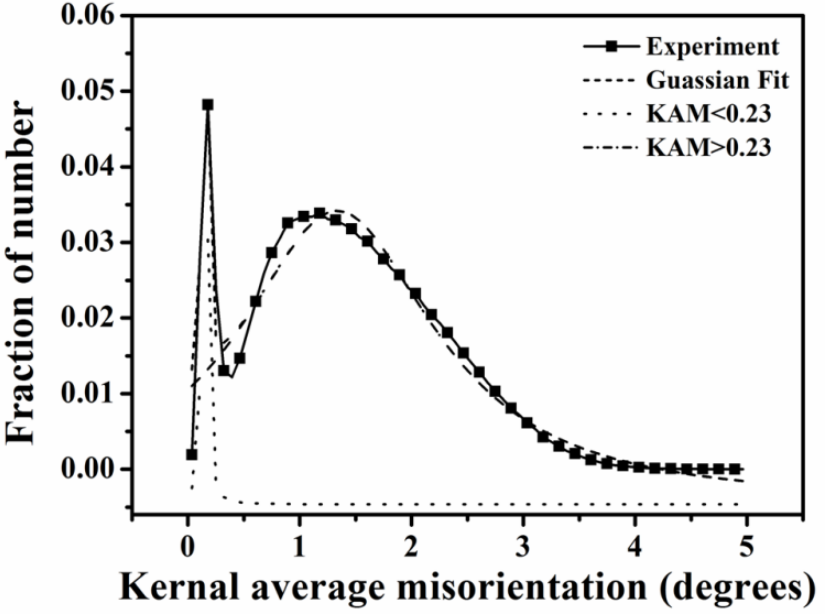

(b)

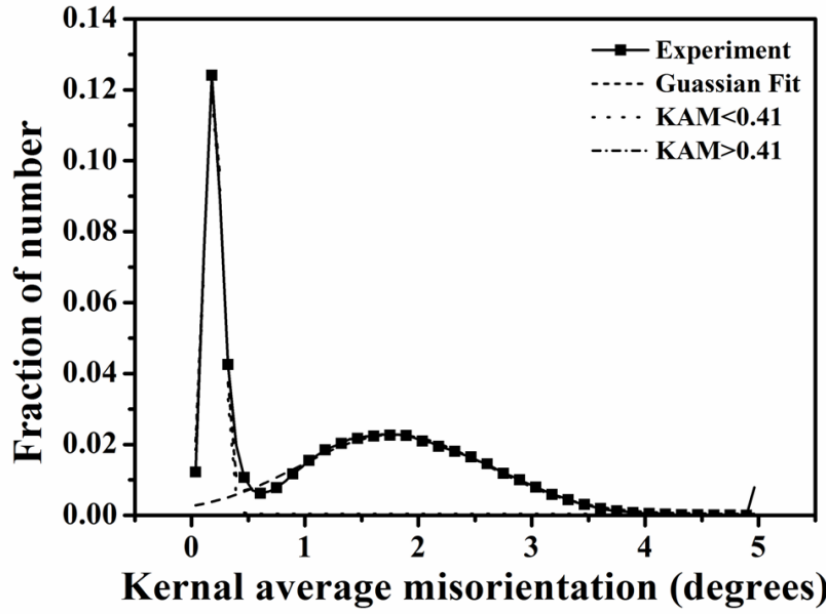

(d)

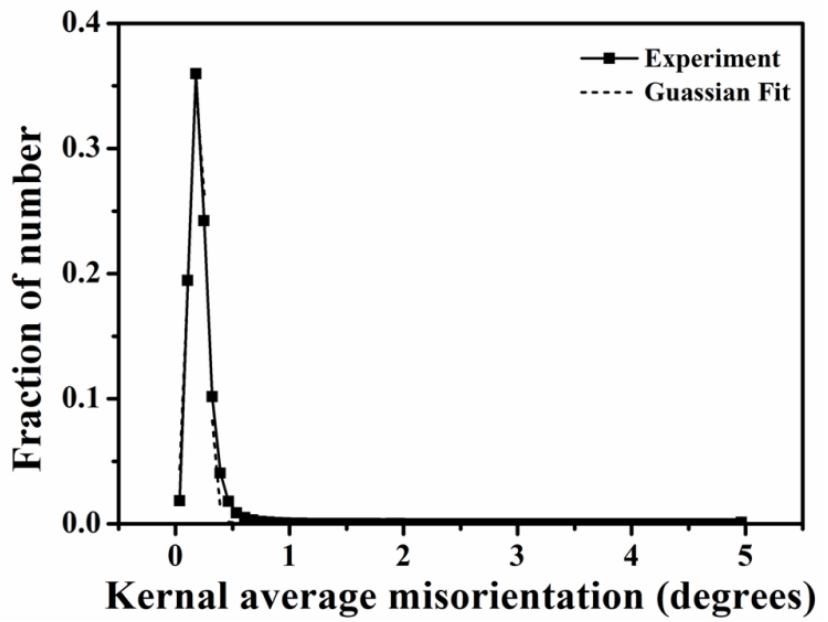

(f)

Figure 1. KAM maps after (a) $1 \mathrm{~min}$; (c) $2 \mathrm{~min}$; and (e) $48 \mathrm{~h}$ and KAM histogram after (b) $1 \mathrm{~min}$; (d) $2 \mathrm{~min}$; and (f) $48 \mathrm{~h}$ for 50\% cold-rolled FePd alloy at $700{ }^{\circ} \mathrm{C}$. (The KAM value ranges from $0^{\circ}$ to $5^{\circ}$, corresponding to white and red. LAGB: Green, HAGB: Black and CSL: Blue). 


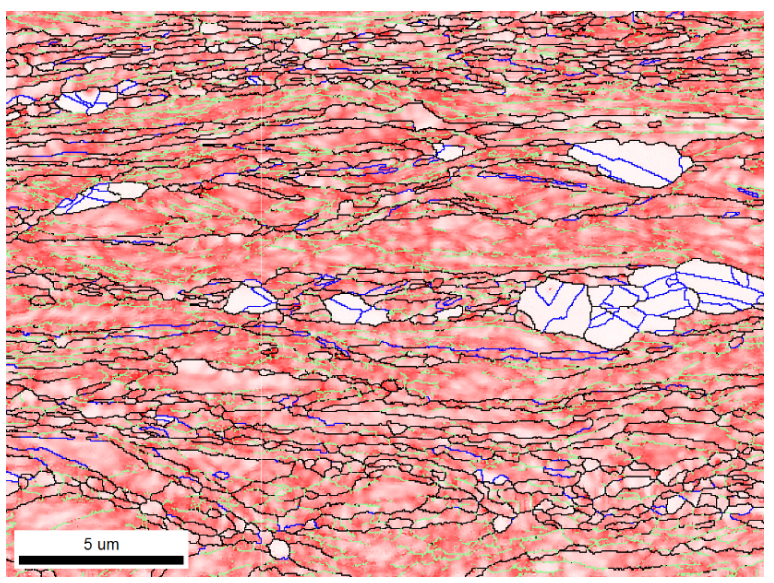

(a)

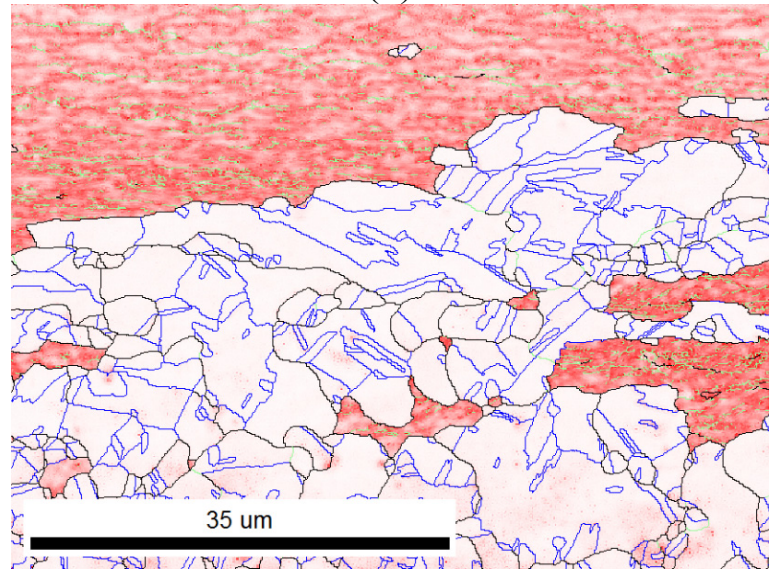

(c)

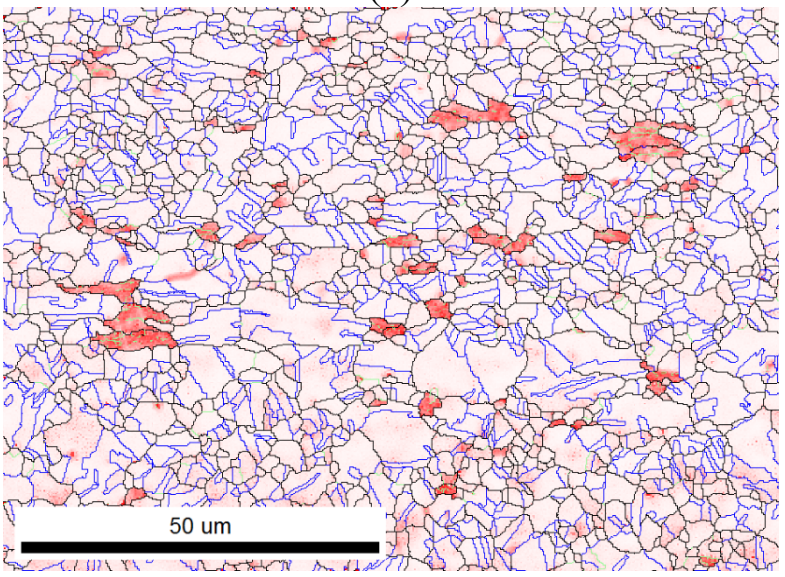

(e)

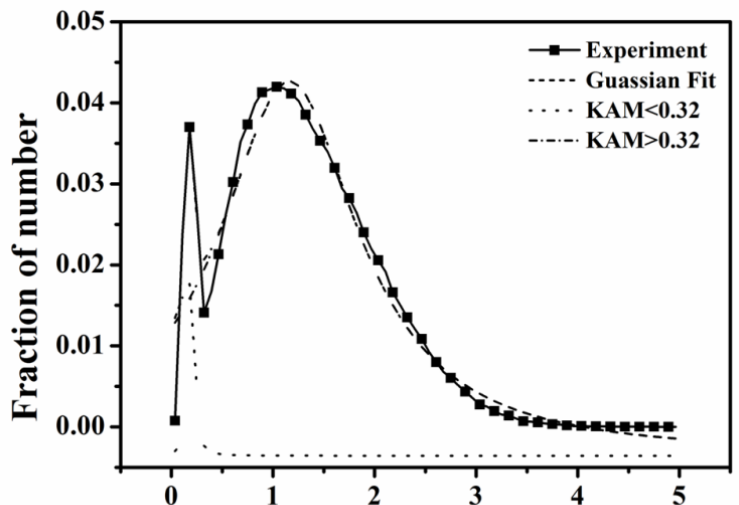

Kernal average misorientation (degrees)

(b)

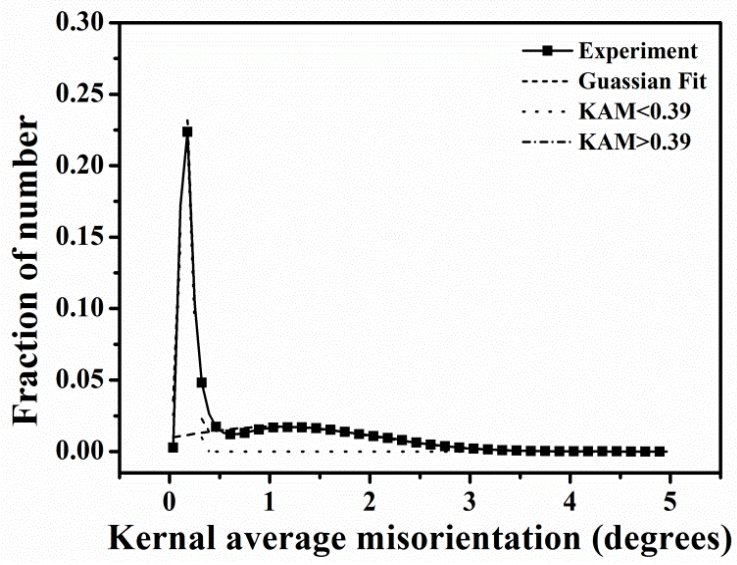

(d)

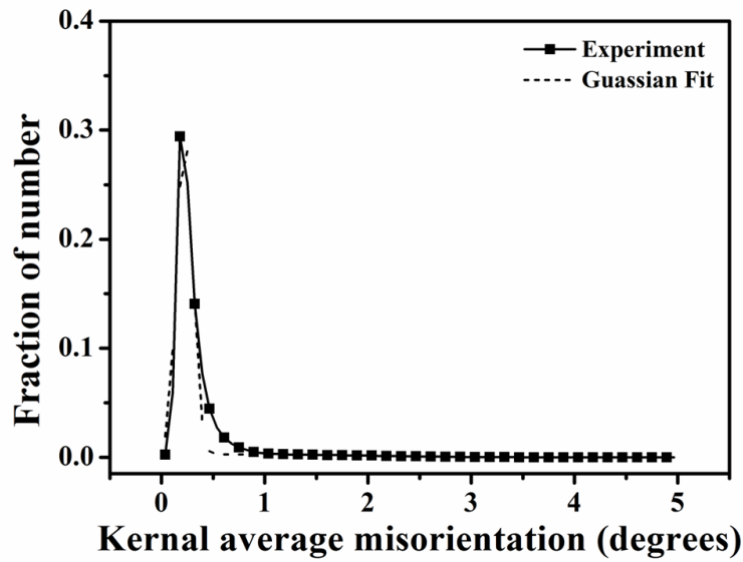

(f)

Figure 2. KAM maps after (a) $10 \mathrm{~s}$; (c) $20 \mathrm{~s}$; and (e) $60 \mathrm{~s}$ and KAM histogram after (b) $10 \mathrm{~s}$; (d) $20 \mathrm{~s}$; and (f) $60 \mathrm{~s}$ for $90 \%$ cold-rolled FePd alloy at $700{ }^{\circ} \mathrm{C}$. The color coding is shown in Figure 1.

Considering the effect of ordering process on recrystallization in a previous study [14], the Avrami exponent $n$ has the values of 0.7 and 1.1 for $50 \%$ and $90 \%$ cold rolling at $530{ }^{\circ} \mathrm{C}$, respectively. In the case of $90 \%$ cold rolling, the twin fraction at $530{ }^{\circ} \mathrm{C}$ is smaller than that at $700{ }^{\circ} \mathrm{C}$. Therefore, the $n$ value at $530{ }^{\circ} \mathrm{C}$ should be larger than that at $700{ }^{\circ} \mathrm{C}$ according to retarding recrystallization because of twin formation. However, the $n$ value at $530{ }^{\circ} \mathrm{C}$ is considerably smaller than that at $700{ }^{\circ} \mathrm{C}$. Mao [35] et al. reported that for cold-rolled $\mathrm{FeCo}$ alloy, the ordered structure state can reduce grain boundary mobility 
and decrease the recrystallization speed in the ordering temperature region. Therefore, the above results indicate that the ordering process performs a considerably greater function than that of twin formation.

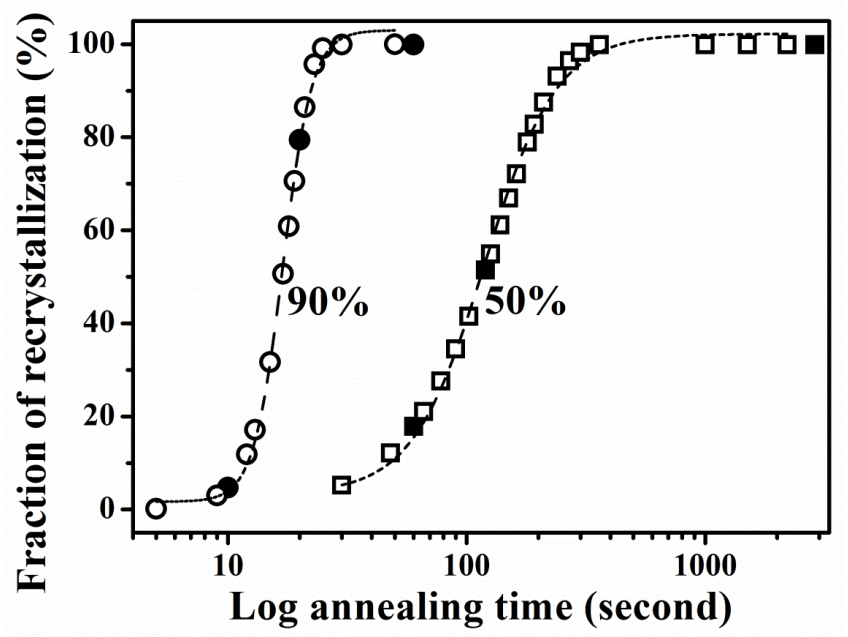

Figure 3. Recrystallization fraction during isothermal annealing for $50 \%$ and $90 \%$ cold-rolled FePd alloy at $700{ }^{\circ} \mathrm{C}$. The solid symbol indicates the results obtained from EBSD, whereas the open symbol represents the predicted values obtained by using the JAMK equation.

Table 1. Recrystallization fraction as a function of annealing time at $530{ }^{\circ} \mathrm{C}$ for $50 \%$ and 90\% cold-rolled FePd alloy.

\begin{tabular}{ccccccc}
\hline Annealing Time (h) & $\mathbf{0 . 5}$ & $\mathbf{1}$ & $\mathbf{4}$ & $\mathbf{1 6}$ & $\mathbf{9 6}$ & $\mathbf{4 0 0}$ \\
\hline $50 \%$ cold rolling & - & $0 \%$ & - & $33 \%$ & $67 \%$ & $100 \%$ \\
$90 \%$ cold rolling & $10 \%$ & $26 \%$ & $67 \%$ & $100 \%$ & - & - \\
\hline
\end{tabular}

\subsection{Effect of Grain Boundaries on Recrystallization}

After discussing recrystallization behavior, we next analyzed the results of the recrystallization microstructure after $50 \%$ and $90 \%$ cold rolling. Figure 4 shows the inverse pole figure maps viewed from the ND and RD direction (called later as ND/RD-IPF) for $50 \%$ cold rolling at $700{ }^{\circ} \mathrm{C}$ for 1,2 , and 2880 min. Figure 5 shows the maps of $90 \%$ cold-rolled FePd alloy viewed from the ND and RD directions. To analyze the texture of recrystallization, $\{111\}$ pole figures were recalculated from orientation distribution function (ODF), as shown in Figure 6. These $\{111\}$ pole figure results after $50 \%$ and $90 \%$ deformation suggest that the newly formed grains during recrystallization reveal a random texture, which is in accordance with the inverse pole figure maps in Figures 1 and 2. Therefore, the grain boundary is characterized in the following. 


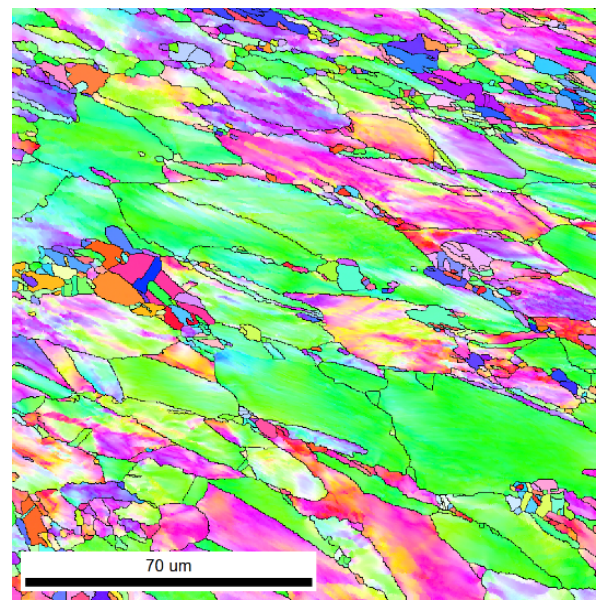

(a)

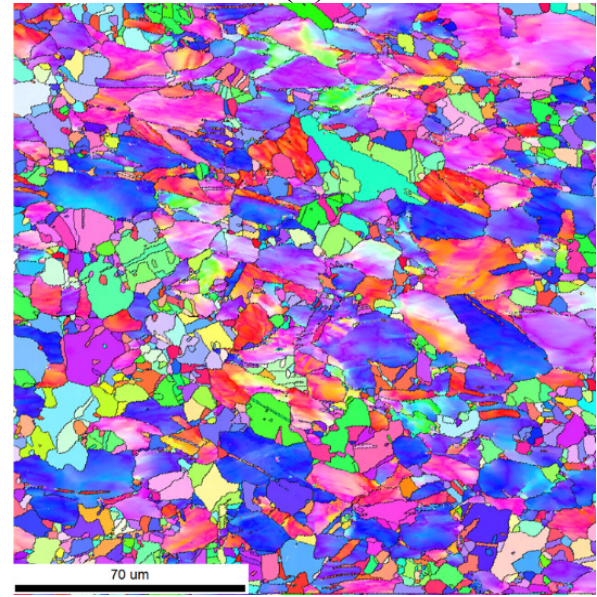

(c)

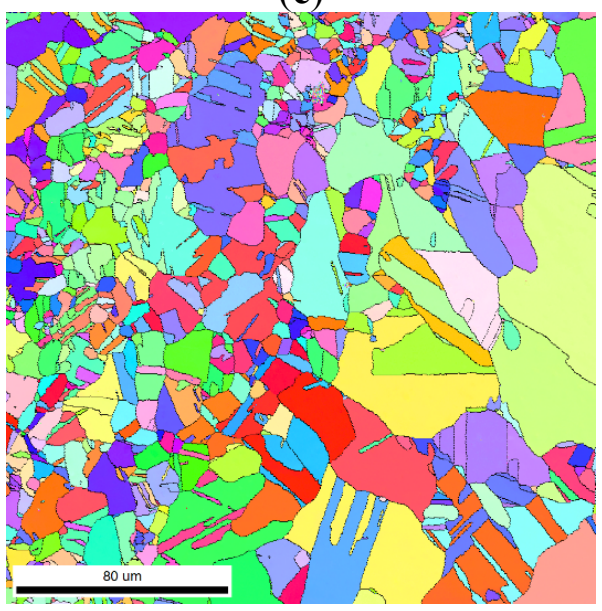

(e)

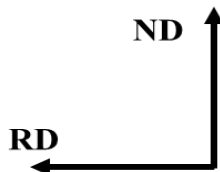

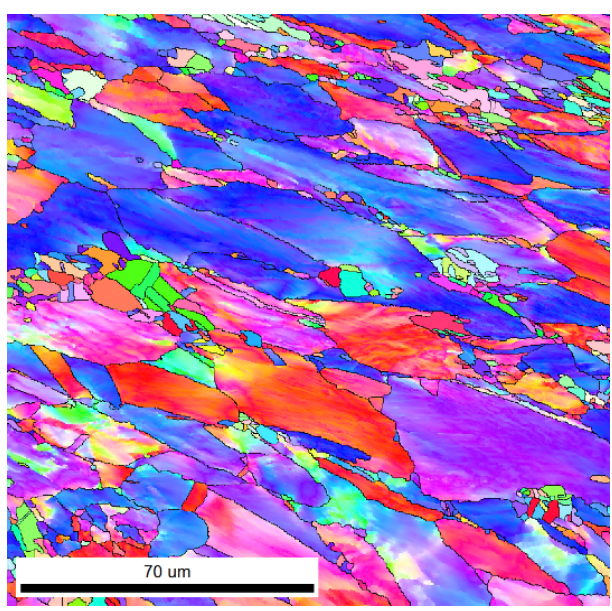

(b)

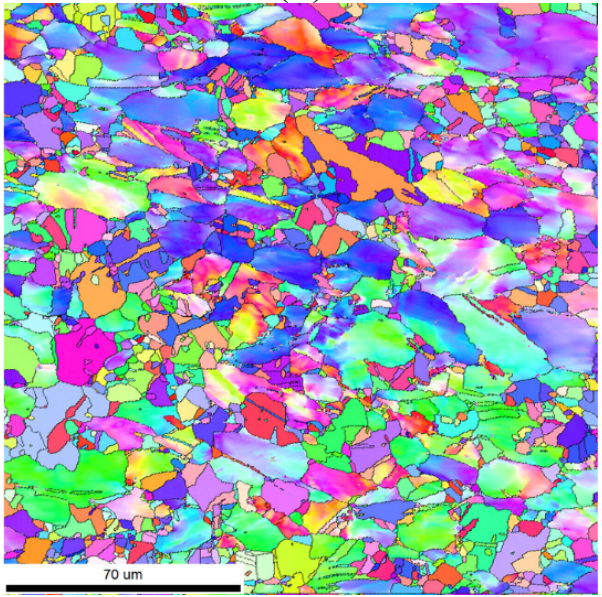

(d)

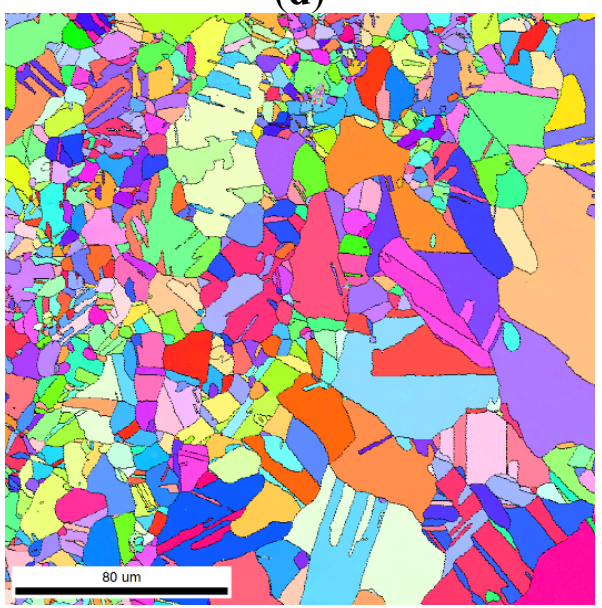

(f)

Grain Boundaries:

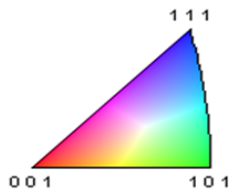

$(\mathbf{g})$

Figure 4. Inverse pole figure (IPF) maps of $50 \%$ cold-rolled $\mathrm{FePd}$ alloy after $700{ }^{\circ} \mathrm{C}$ annealing for (a,b) $1 \mathrm{~min}$; (c,d) $2 \mathrm{~min}$; and (e,f) $48 \mathrm{~h}$. (g) The sample coordinates of ND and RD, and the corresponding color coding of the IPF in terms of ND. 


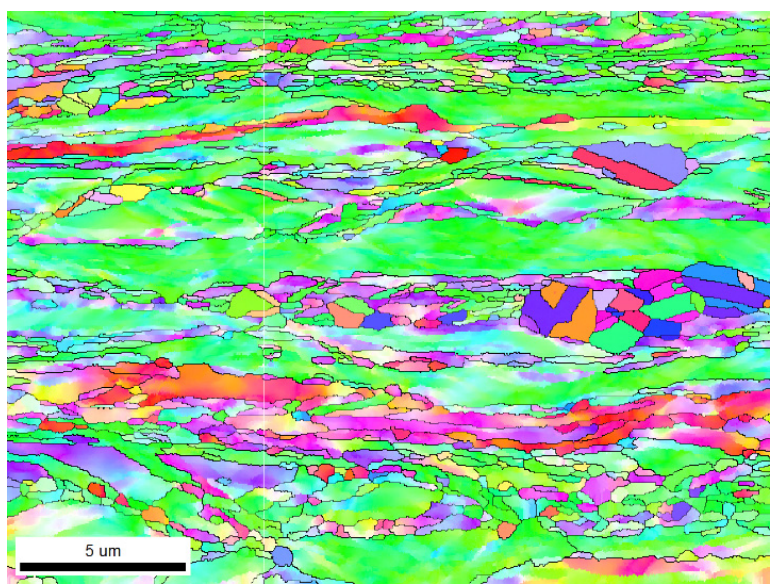

(a)

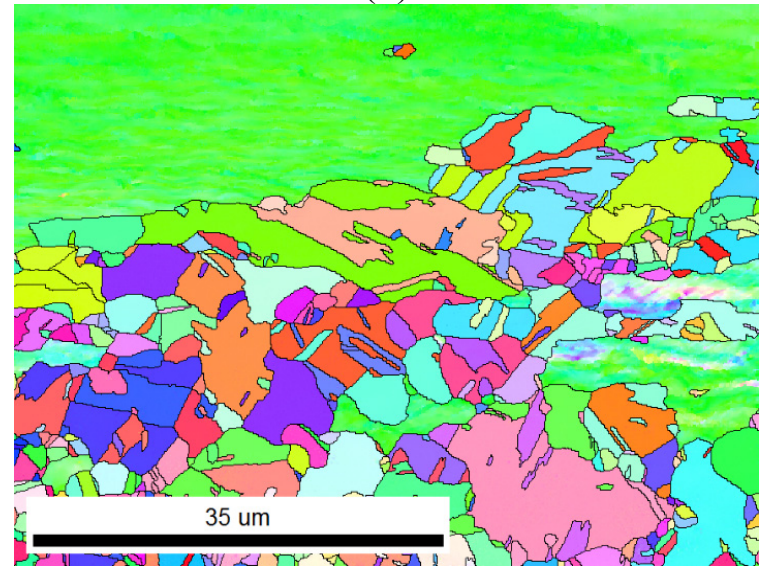

(c)

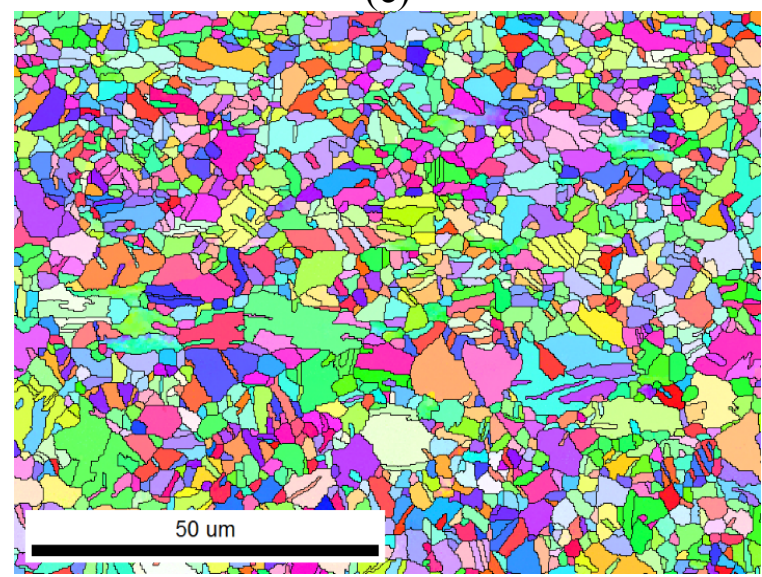

(e)

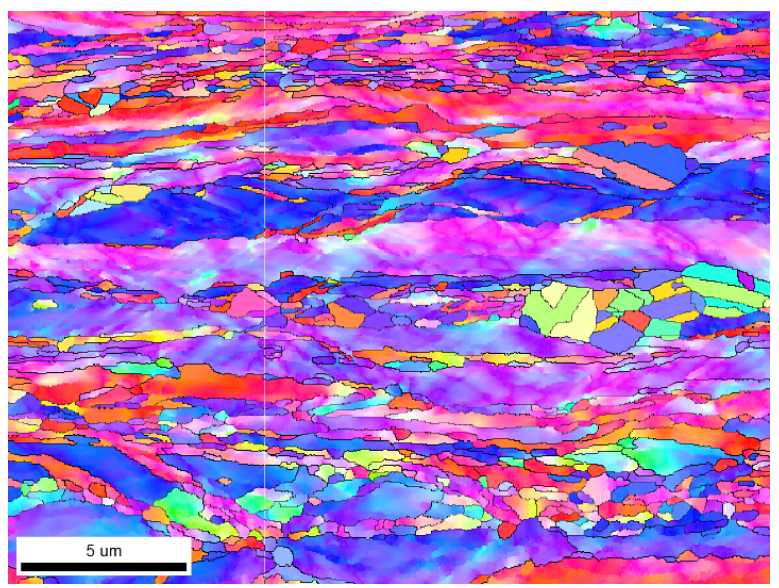

(b)

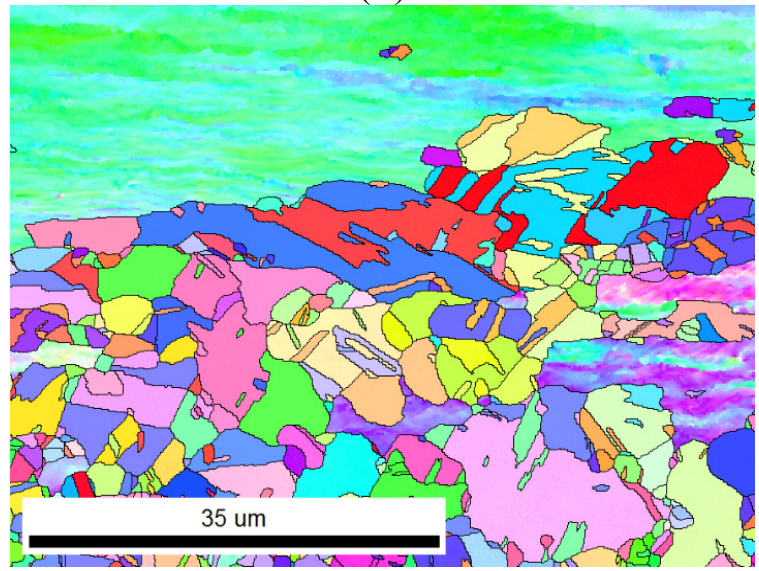

(d)

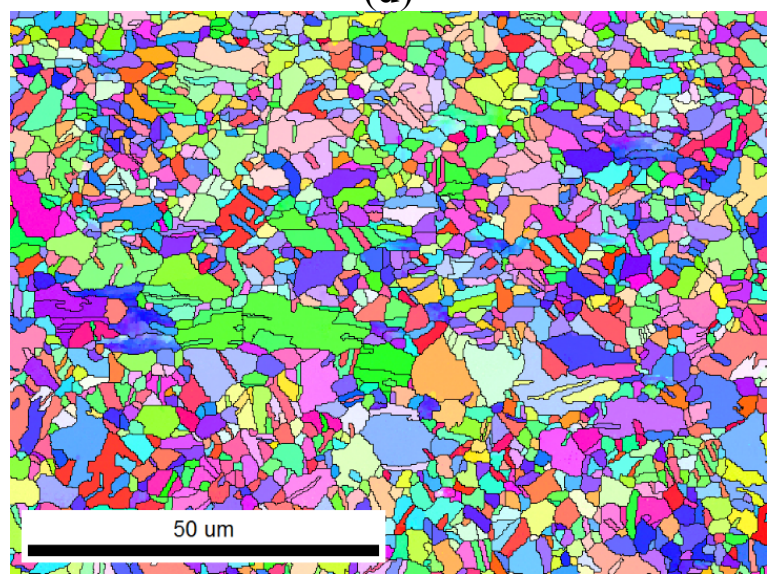

(f)

Figure 5. IPF maps of $90 \%$ cold-rolled FePd alloy after $700{ }^{\circ} \mathrm{C}$ annealing for $(\mathbf{a}, \mathbf{b}) 10 \mathrm{~s}$; (c,d) $20 \mathrm{~s}$; and (e,f) $60 \mathrm{~s}$. The corresponding color coding of the IPF is in terms of ND for $(\mathbf{a}, \mathbf{c}, \mathbf{e})$ and $\mathrm{RD}$ for $(\mathbf{b}, \mathbf{d}, \mathbf{f})$.

We describe the character of grain boundaries according to the misorientation angle of two oriented grains. Here, three different types of grain boundaries are low-angle grain boundaries (called LAGBs) with misorientation of $5^{\circ}-15^{\circ}$, high-angle grain boundaries (HAGBs) with misorientation $>15^{\circ}$ and special grain boundaries expressed in a coincidence site lattice (CSL) [32]. Figure 7a shows the grain boundary character distribution as a function of recrystallization fraction for $50 \%$ cold-rolled $\mathrm{FePd}$ 
alloy at $700{ }^{\circ} \mathrm{C}$. It is found that the initial deformation microstructure of $50 \%$ deformation has $82 \%$ LAGB, 15\% HAGB and 3\% CSL. As increasing the annealing time from $1 \mathrm{~min}$ to $48 \mathrm{~h}$ corresponds to $17 \%$ to $83 \%$ recrystallization, the number fraction of LAGB is reduced but the number fractions of both HAGB and CSL are increased. This observation suggests the increase in boundaries of HAGB and CSL with consuming LAGB. In another case of $90 \%$ cold-rolled FePd alloy, it is observed to be the same as with $50 \%$, but the difference between them lies in the ratio of HAGB to CSL.

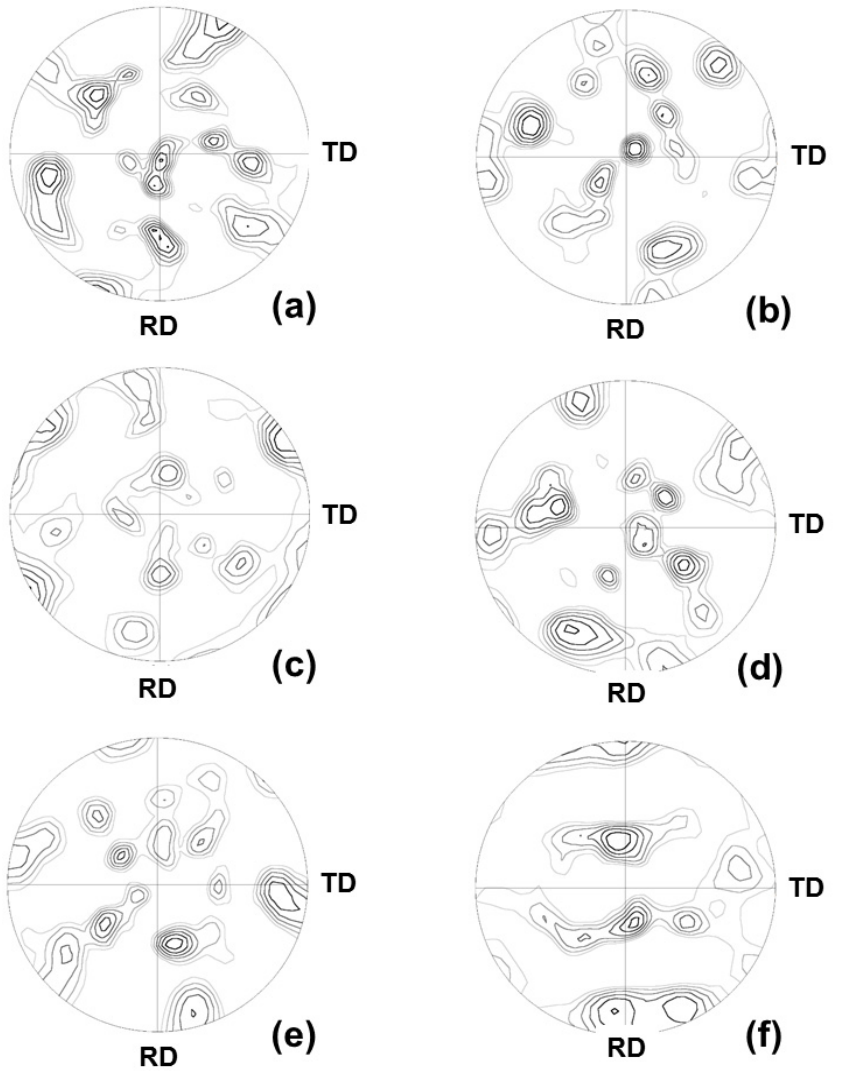

Figure 6. $\{111\}$ pole figures of FePd alloy at $700{ }^{\circ} \mathrm{C}$ after (a) $1 \mathrm{~min}$; (c) $2 \mathrm{~min}$; and (e) $48 \mathrm{~h}$ for 50\% cold rolling, and after (b) $10 \mathrm{~s}$; (d) $20 \mathrm{~s}$; and (f) $60 \mathrm{~s}$ for $90 \%$ cold rolling.

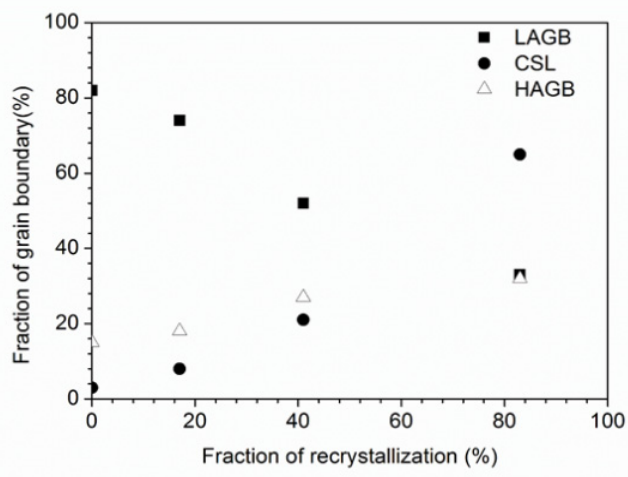

(a)

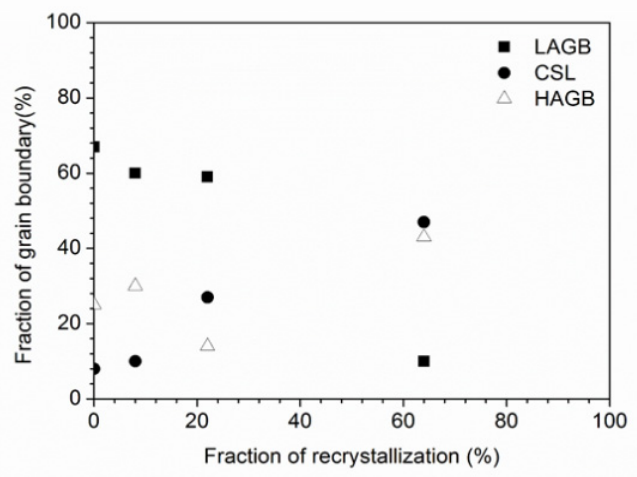

(b)

Figure 7. Fraction of grain boundaries as a function of recrystallization fraction for (a) $50 \%$ and (b) $90 \%$ cold-rolled FePd alloy at $700{ }^{\circ} \mathrm{C}$. (LAGB: Low-angle boundary with misorientation between $5^{\circ}$ and $15^{\circ}$, HAGB: High angle boundary with misorientation $>15^{\circ}$ and CSL: Coincidence site lattice). 
The succession of grain boundaries indicates a change in boundaries at different stages of recrystallization as mentioned above. In order to reveal the partially recrystallized grain boundaries at the early stage, the KAM maps were overlapped with LAGB, HAGB and CSL boundaries in Figures 8 and 9 for $50 \%$ and $90 \%$, respectively. The kernel average misorientation map can be assumed to be a dislocation density distribution map in different grains [13,26]. After 50\% and 90\% deformation LAGB reveals random boundaries, but after one minute of annealing, some LAGBs can be retained at the early stage of recrystallization in Figure 10a. At this stage LAGB distribution reveals "regular" boundaries in Figure 10a which occur in the vicinity of high KAM, that is, regions with a high density of dislocations. The development of LAGB distribution from "random" to "regular" can be explained with the mechanisms of thermally activated glide and cross-slip after a short annealing time. These mechanisms lead to a decrease in dislocation density and the LAGB number.

In addition to the formation of regular LAGBs, two combination grain boundaries are observed; one is LAGB/HAGB, and the other CSL/HAGB, as shown in Figure 10b,c. Both types of combination grain boundaries also have high KAM as mentioned in LAGBs. In the case of $50 \%$ deformation with one minute annealing, KAM $>0.23$ is assumed in deformed state and $\mathrm{KAM}<0.23$ in recrystallized state in Figure 1b. These boundaries of LAGB, LAGB/HAGB and CSL/HAGB have KAM $>0.23$ belonging to the deformed state. LAGB boundaries occur firstly in deformed state and can remain in the early stage of recrystallization. However, CSL boundaries with KAM $<0.23$ in Figure 10d are finally formed during recrystallization. Between LAGB and CSL there is the transition state of LAGB/HAGB and CSL/HAGB. LAGB/HAGB and CSL/HAGB boundaries with KAM $>0.23$ suggest that both of them are not fully recrystallized as the case of CSL, that is, the transition state. It is usually assumed that low-angle grain boundaries are immobile. However, Winning and Raabe [36] reported that low-angle grain boundaries can move during recrystallization. This finding can be explained by the transformation from LAGBs to the transition state of LAGB/HAGB. After the LAGB transformation, HAGBs can be transformed to the transition state of CSL/HAGB due the low interface energy of CSL. These observations are also found in 90\% deformation in Figure 11. Therefore, we can conclude that during the recrystallization process, grain boundaries can transform from LAGB through HAGB and to CSL boundaries.

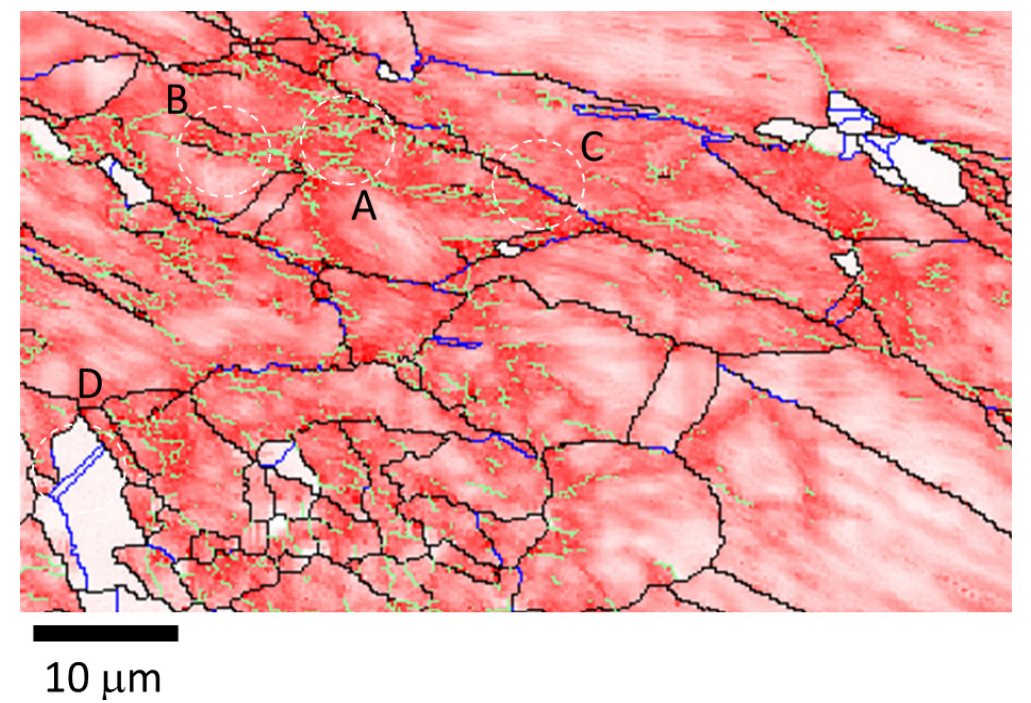

Figure 8. Magnification image of KAM map extracted from Figure 1a for 50\% cold-rolled FePd alloy after $1 \mathrm{~min}$ annealing at $700{ }^{\circ} \mathrm{C}$. The color code is shown in Figure 1. 


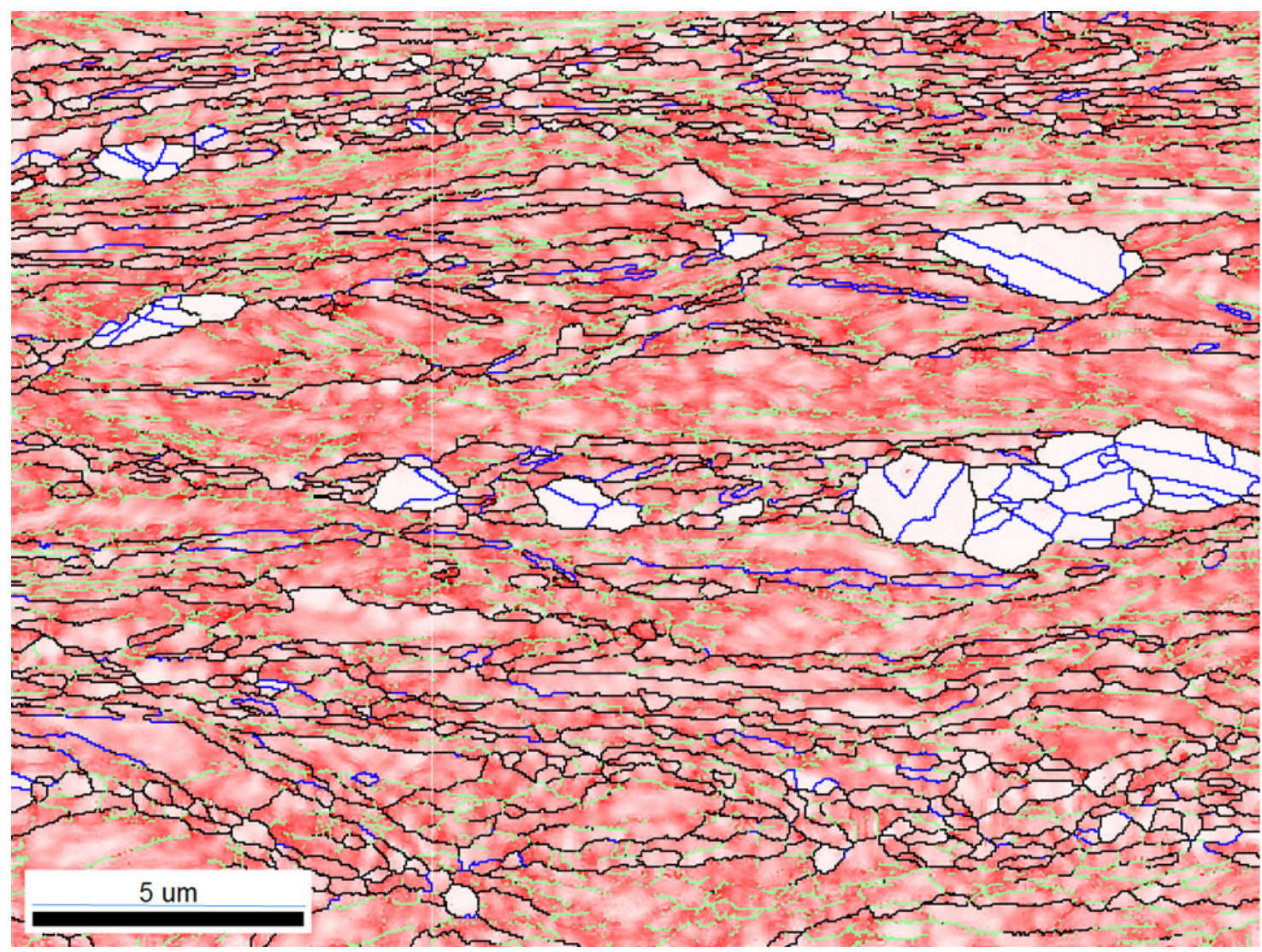

Figure 9. Magnification image of KAM map extracted from Figure 2a for 90\% cold-rolled FePd alloy after $10 \mathrm{~s}$ annealing at $700{ }^{\circ} \mathrm{C}$. The color code is shown in Figure 1.
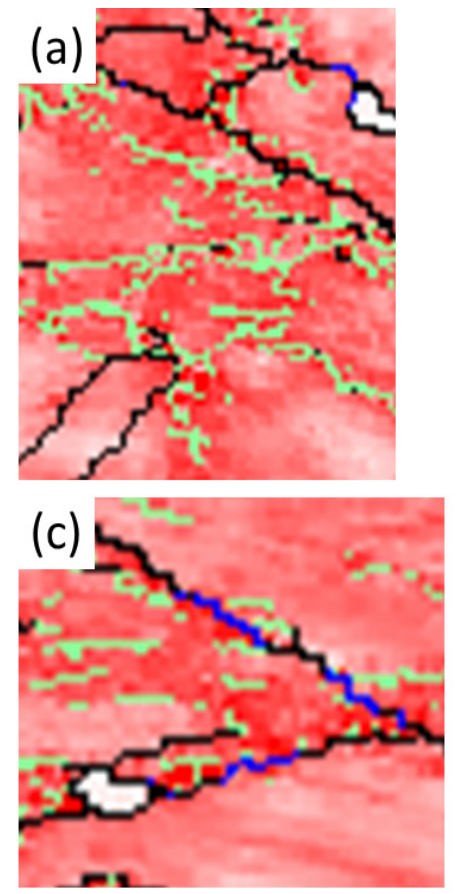
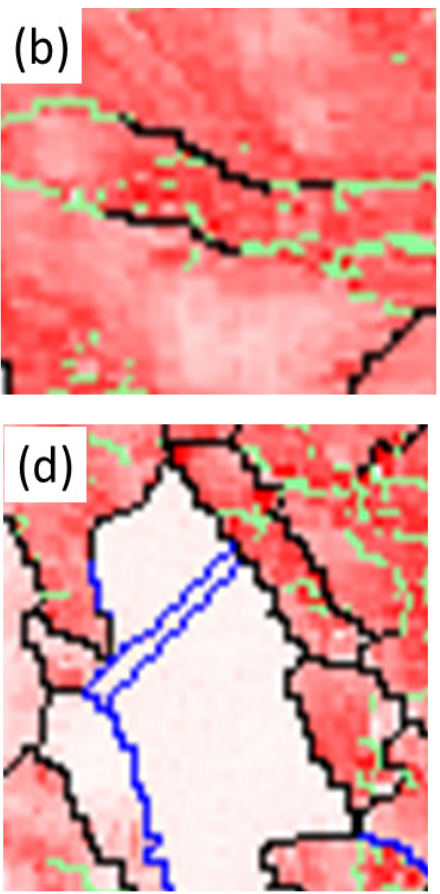

Figure 10. Magnification image of (a) A area with LAGBs; (b) B area with HAGB and LAGB; (c) C area with HAGB and CSL; and (d) D area with CSLs for 50\% cold-rolled FePd alloy at $700{ }^{\circ} \mathrm{C}$ after $1 \mathrm{~min}$. A, B, C and D symbols indicate the areas of image magnification marked in white dash lines in Figure 8. 


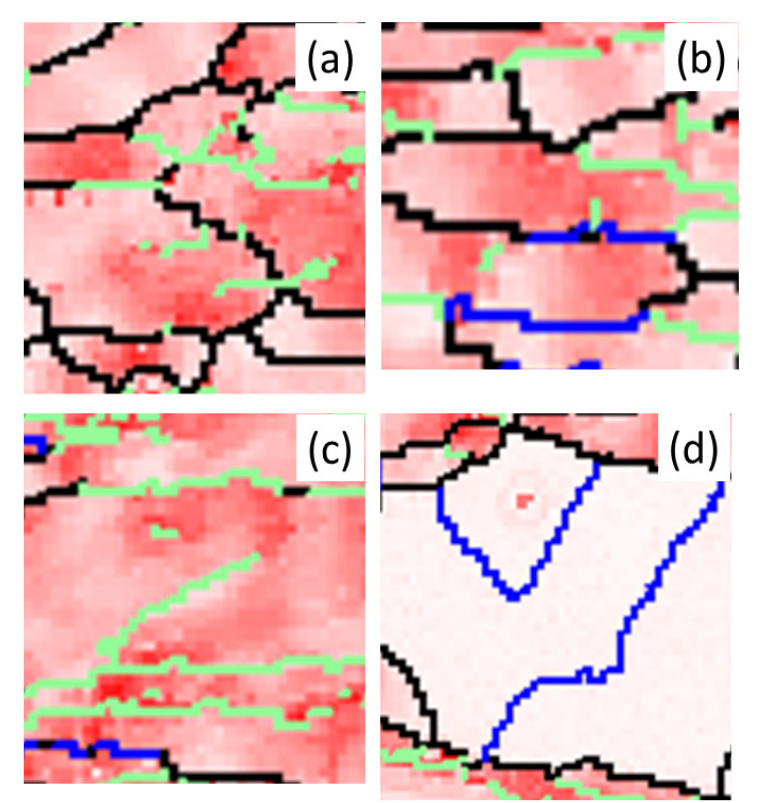

Figure 11. Magnification image of (a) A area with LAGBs; (b) B area with HAGB and LAGB; (c) $\mathrm{C}$ area with HAGB and CSL; and (d) D area with CSLs for 90\% cold-rolled FePd alloy at $700{ }^{\circ} \mathrm{C}$ after $1 \mathrm{~min}$. A, B,C and D symbols indicate the areas of image magnification marked in white dash lines in Figure 8.

\section{Conclusions}

After 50\% and 90\% reduction in FePd alloy, the exponent $n$ of 1.9 and 4.9 indicate one- and three-dimensional growth at constant-rate nucleation, respectively. Compared to $90 \%$ reduction, the smaller $n$ value of $50 \%$ reduction is due to its higher twin fraction. During recrystallization, HAGB and CSL increase with the consumption of LAGB at first, and the later increase in CSL is due to a decrease in HAGB. Therefore, we observed that a change in grain boundaries occurs from LAGB through HAGB to CSL during recrystallization for $50 \%$ and $90 \%$ reduction. Furthermore, the newly formed grains reveal a random texture at the early stage of recrystallization for $50 \%$ and $90 \%$ reduction.

\section{Acknowledgments}

The authors would gratefully like to thank the Ministry of Science and Technology (MOST) for providing funding to support the project (103-2221-E-006-060-MY3).

\section{Author Contributions}

Hung-Pin Lin and Jui-Chao Kuo conceived and designed the experiments; Hung-Pin Lin performed the experiments; Hung-Pin Lin and Jui-Chao Kuo analyzed the data; Delphic Chen contributed reagents/materials/analysis tools; Jui-Chao Kuo wrote the paper.

\section{Conflicts of Interest}

The authors declare no conflict of interest. 


\section{References}

1. Yamaguchi, M.; Umakoshi, Y. The deformation behaviour of intermetallic superlattice compounds. Prog. Mater. Sci. 1990, 34, 1-148.

2. Weller, D.; Moser, A. Thermal effect limits in ultrahigh density magnetic recording. IEEE Trans. Magn. 1999, 35, 4423-4439.

3. Klemmer, T.; Hoydick, D.; Okumura, H.; Zhang, B.; Soffa, W.A. Magnetic hardening and coercivity mechanisms in L10 ordered FePd ferromagnets. Scr. Metall. Mater. 1995, 33, 1793-1805.

4. Fingers, R.T.; Rubertus, C.S. Application of high temperature magnetic materials. IEEE Trans. Magn. 2000, 36, 3373-3375.

5. Sundar, R.S.; Deevi, S.C. Soft magnetic FeCo alloys: Alloy development, processing, and properties. Int. Mater. Rev. 2005, 50, 157-192.

6. Wang, L.; Fan, Z.; Roy, A.G.; Laughlin, D.E. Effect of atomic ordering on the Curie temperature of FePd $L 1_{0}$ type alloys. J. Appl. Phys. 2004, 95, 7483-7485.

7. Smallman, R.E.; Green, D. The dependence of rolling texture on stacking fault energy. Acta Metall. 1964, 12, 145-154.

8. Smith, T.G. Proceedings of the ICOTOM5: Texture of Materials; Gottstein, G., Luecke, K., Eds.; Springer Verlag: Berlin, Germany, 1978; Volume 2, p. 485.

9. Yushkov, V.I.; Adamescu, R.A.; Machnev, Y.S.; Gapeka, T.M.; Geld, P.V. The developments in texture in stainless steel. Mater. Sci. Eng. 1984, 64, 157-169.

10. Donadille, C.; Valle, R.; Dervin, P.; Penelle, R. Development of texture and microstructure during cold-rolling and annealing of F.C.C. alloys: Example of an austenitic stainless steel. Acta Metall. 1989, 37, 1547-1571.

11. Dickson, M.J.; Green, D. The cold-rolling and primary-recrystallisation textures of $18 \%$ chromium steels containing 10\%, 12\% and 14\% Nickel. Mater. Sci. Eng. 1969, 4, 304-312.

12. Randle, V. Simulation of mesotexture between deformed and recrystallised microstructures. Mater. Sci. Technol. 1990, 6, 1231-1235.

13. Chowdhury, S.G.; Datta, S.; Kumara, B.R.; De, P.K.; Ghosh, R.N. Randomization of texture during recrystallization of austenite in a cold rolled metastable austenitic stainless steel. Mater. Sci. Eng. A 2007, 443, 114-119.

14. Lin, H.P.; Chen, Y.C.; Chen, D.; Kuo, J.C. Effect of cold deformation on the recrystallization behavior of FePd alloy at the ordering temperature using electron backscatter diffraction. Mater. Charact. 2014, 94, 138-148.

15. Hu, H. Texture of metals. Texture 1974, 1, 233-258.

16. Raabe, D. Texture and microstructure evolution during cold rolling of a strip cast and of a hot rolled austenitic stainless steel. Acta Mater. 1997, 45, 1137-1151.

17. Virnich, K.H.; Koehlhoff, G.D.; Luecke, K.; Pospiech, J. Proceedings of the ICOTOM5: Texture of Materials; Gottstein, G., Luecke, K., Eds.; Springer Verlag: Berlin, Germany, 1998; Volume 1.

18. Humphreys, F.J. Modelling mechanisms and microstructures of recrystallization. Mater. Sci. Technol. 1992, 8, 135-144.

19. Eichelkraut, H.; Hirsch, J.; Luecke, K. Rolling and Recrystallization Textures in Copper-Germanium Alloys. Z. Metallkd. 1984, 75, 113-123. 
20. Washburn, J.; Parker, E.R. Kinking in zinc single-crystal tension specimens. J. Metals 1952, 4, 1076-1078.

21. Li, C.H.; Edwards, E.H.; Washburn, J.; Parker, E.R. Stress-induced movement of crystal boundaries. Acta Metall. 1953, 1, 223-229.

22. Winning, M.; Gottstein, G.; Shvindlerman, L.S. Stress induced grain boundary motion. Acta Mater. 2001, 49, 211-219.

23. Winning, M. Motion of $<100>$-tilt grain boundaries. Acta Mater. 2003, 51, 6465-6475.

24. Heinrich, M.; Haider, F. Primary recrystallization in slightly tensile deformed aluminium single crystals. Philos. Mag. 1996, 74, 1047-1057.

25. Luecke, K. Proceedings of the ICOTOM7: Proceedings Texture of Materials; Brakman, C.M., Jongenburger, P., Mittemiejer, E.J., Eds.; Netherlands Society of Materials Science: Noordwijkerhout, The Netherlands, 1984.

26. Lin, H.P.; Ng, T.S.; Kuo, J.C.; Chen, Y.C.; Chen, C.L.; Ding, S.X. EBSD Study on Crystallographic Texture and Microstructure Development of Cold-Rolled FePd Alloy. Mater. Charact. 2014, 93, 167-172.

27. Kolmogorov, A.N. A statistical theory for the recrystallization of metals. Izv. Akad. Nauk SSSR Ser. Matem. 1937, 1, 355-359.

28. Johnson, W.A.; Mehl, R.F. Reaction kinetics in processes of nucleation and growth. Trans. AIME 1939, 135, 396-415.

29. Avrami, M. Kinetics of phase change. I general theory. J. Chem. Phys. 1939, 7, 1103-1112.

30. Avrami, M. Kinetics of phase change. II: Transformation-time relations for random distribution of nuclei. J. Chem. Phys. 1940, 8, 212-224.

31. Avrami, M. Granulation, phase change, and microstructure kinetics of phase change. III. J. Chem. Phys. 1941, 9, 177-184.

32. Humphreys, F.J.; Hatherly, M. Recrystallization and Related Annealing Phenomena, 2nd ed.; Elservier: New York, NY, USA, 2004.

33. Cahn, J.W. Transformation kinetics during continuous cooling. Acta Metall. 1956, 4, 572-575.

34. Mandal, S.; Bhaduri, A.K.; Sarma, V.S. Influence of state of stress on dynamic recrystallization in a titanium-modified austenitic stainless steel. Metall. Mater. Trans. A 2012, 43, 410-414.

35. Mao, W.; Zhu, G.; Yu, Y. Influence of order-disorder transition on the recrystallization behaviors of a cold rolled FeCo alloy. Z. Metallkd 2000, 91, 211-214.

36. Winning, M.; Raabe, D. Applications of Texture Analysis: Ceramic Transactions; Rollett, A.D., Ed.; The American Ceramic Society: Hoboken, NJ, USA, 2009; Volume 201.

(C) 2015 by the authors; licensee MDPI, Basel, Switzerland. This article is an open access article distributed under the terms and conditions of the Creative Commons Attribution license (http://creativecommons.org/licenses/by/4.0/). 